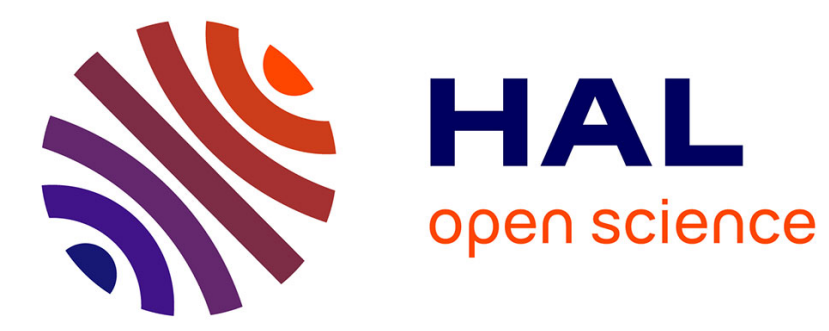

\title{
Effectiveness of thermo-compression for manufacturing native starch bulk materials
}

Arnaud Regazzi, Pierre J.J. Dumont, Barthelemy Harthong, Didier Imbault, Robert Peyroux, Jean-Luc Putaux

\section{- To cite this version:}

Arnaud Regazzi, Pierre J.J. Dumont, Barthelemy Harthong, Didier Imbault, Robert Peyroux, et al.. Effectiveness of thermo-compression for manufacturing native starch bulk materials. Journal of Materials Science, 2016, 51 (11), pp.5146 - 5159. 10.1007/s10853-016-9817-7 . hal-01828910

\section{HAL Id: hal-01828910 https://hal.science/hal-01828910}

Submitted on 27 Jul 2018

HAL is a multi-disciplinary open access archive for the deposit and dissemination of scientific research documents, whether they are published or not. The documents may come from teaching and research institutions in France or abroad, or from public or private research centers.
L'archive ouverte pluridisciplinaire HAL, est destinée au dépôt et à la diffusion de documents scientifiques de niveau recherche, publiés ou non, émanant des établissements d'enseignement et de recherche français ou étrangers, des laboratoires publics ou privés. 


\title{
Effectiveness of thermo-compression for manufacturing native starch bulk materials
}

\author{
Arnaud Regazzi $i^{1,2,3,4,5}$, Pierre J. J. Dumont ${ }^{1,2,3,8, \star}$, Barthélémy Harthong ${ }^{4,5}$, Didier Imbault ${ }^{4,5}$, \\ Robert Peyroux ${ }^{4,5}$, and Jean-Luc Putaux ${ }^{6,7}$ \\ 'Univ. Grenoble Alpes, LGP2, 38000 Grenoble, France \\ ${ }^{2}$ CNRS, LGP2, 38000 Grenoble, France \\ ${ }^{3}$ Agefpi, LGP2, 38000 Grenoble, France \\ ${ }^{4}$ Univ. Grenoble Alpes, 3SR Lab, 38000 Grenoble, France \\ ${ }^{5}$ CNRS, 3SR Lab, 38000 Grenoble, France \\ ${ }^{6}$ Univ. Grenoble Alpes, CERMAV, 38000 Grenoble, France \\ ${ }^{7}$ CNRS, CERMAV, 38000 Grenoble, France \\ Present address: \\ ${ }^{8}$ Université de Lyon, LaMCOS, INSA-Lyon, CNRS UMR5259, 69621 Lyon, France
}

\begin{abstract}
In this study, thermo-compression molding was used to fabricate bulk materials from native starch powder. The objective was to determine the process parameters that enabled the welding of starch granules while preserving their crystallinity. The effects of forming parameters such as temperature, compression stress, and water content on the microstructural and mechanical properties of the starch samples were studied. For the optimal forming conditions, good compaction and cohesion of starch granules were obtained, while successfully preserving their native crystalline structure. The flexural Young's modulus of the best samples reached an average value of $3 \mathrm{GPa}$ and the flexural strength reached $10 \mathrm{MPa}$. However, these materials also exhibited unwanted cracks. The potential origin of these defects was associated to the heterogeneous distribution of water during processing as well as thermal shrinkage, moisture uptake, and viscoelastic recovery that occurred after the mold ejection.
\end{abstract}

\section{Introduction}

The need for sustainable materials has prompted the development of biopolymer matrices and biobased reinforcing fibers. Several biobased constituents with excellent mechanical properties can be used to elaborate biocomposites with enhanced mechanical properties. For instance, plant and wood fibers offer excellent specific mechanical properties. Biobased constituents such as starch granule powders also show very good mechanical properties because of their nanoscale semicrystalline structure [1-3]. However,

Address correspondence to E-mail: pierre.dumont@insa-lyon.fr 


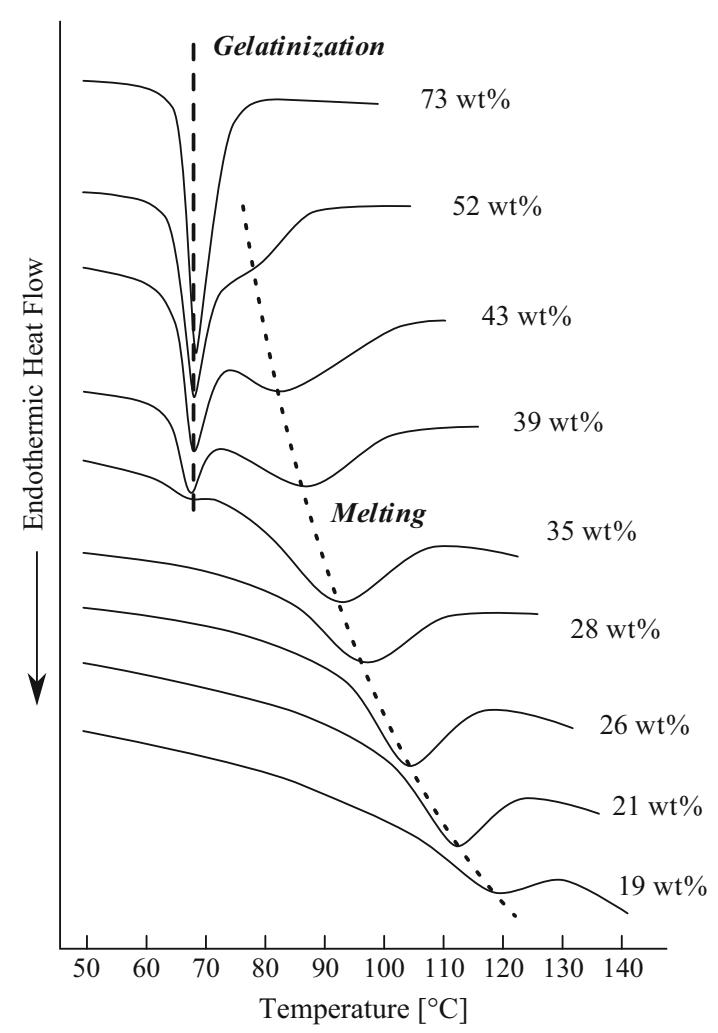

Figure 1 DSC thermograms of potato starch recorded at a heating rate of $10{ }^{\circ} \mathrm{C} \mathrm{min}^{-1}$ as a function of the water volume fraction (reproduced and adapted from Donovan [6] with the kind permission of John Wiley \& Sons, Inc.).

current forming routes often result in limited mechanical properties because of the disruption of the crystal structure of the native starch granules [4].

Starch granules are semicrystalline particles with a crystallinity index that depends on the water content. Amylopectin, the branched polysaccharide constituting the main fraction of native starch, is considered to bear the crystallinity through the clustered organization of its short linear segments into double helices. Depending on the botanical origin, native starch granules present two main types of crystal structures, namely $\mathrm{A}$ and $\mathrm{B}$, that correspond to different organizations of parallel double helices (monoclinic and hexagonal, respectively) and water contents [2].

Several studies reported on the complex thermal behavior of native starch [5] and in particular its dependency on water content [6-8]. In starch-water systems, the increase in water content induces a lowering of the melting temperature, as shown in Fig. 1. Gelatinization occurs for water contents above $35 \mathrm{wt} \%$ and, in such conditions, the gelatinization temperature is independent of water content (Fig. 1).
Water is also a plasticizer for starch and is expected to improve deformability of starch granules by increasing the mobility of macromolecular chains [9]. This property can be used to build dense assemblies of starch granules by compaction where cohesion results from the sintering/welding of starch granules.

This study aimed at developing an original processing route to prepare cohesive starch matrices while preserving the intrinsic mechanical behavior of starch granules. The conditions promoting the sintering of starch powders while preserving their native crystallinity and keeping water content and temperature below gelatinization conditions were experimentally determined. This article describes the effects of water content, compression stress, and temperature on the microstructure and mechanical properties of samples processed by thermo-compression molding. The effects of variations in water content on sample defects during processing were discussed, as well as thermal shrinkage, hygroscopic swelling, and viscoelastic recovery after ejection.

\section{Materials and methods}

\section{Materials}

Waxy maize starch C*Gel 04201 from Cargill was used for this study. This type of starch was chosen because of its high amylopectin content (about $99 \%$ ).

\section{Processing methods}

\section{Starch moisturizing}

To evaluate the influence of moisture content on processing, starch granules were conditioned using different drying/hydration techniques as summarized in Table 1 . The water content in the materials was evaluated using a moisture analyzer (Ohaus MB35, Parsippany, NJ, USA). Each sample was heated up to $105^{\circ} \mathrm{C}$ under a halogen lamp, while its mass was recorded. The measurement of initial water content was completed immediately after mass stabilization. Starch hydrated by mixing was prepared following the procedure described by Day et al. [8]. The appropriate amount of water was slowly poured in the as-received starch powder during mixing with a blender. The mixture was stored in a refrigerator during at least 1 week before characterization. To avoid a complete loss of crystalline structure by gelatinization, water content never exceeded $25 \mathrm{wt} \%$. 
Table 1 The different moisture conditioning techniques used in this study

\begin{tabular}{llll}
\hline Technique & Temperature $\left({ }^{\circ} \mathrm{C}\right)$ & Time (days) & Water content (wt\%) \\
\hline Oven-dried & 60 & 3 & 6 \\
No treatment (as-received) & 23 & - & 13 \\
Hydrated in environmental chamber (95 \% r.h.) & 45 & 5 & 19 \\
Hydrated by mixing with water & 23 & 7 & $16.5-25$ \\
\hline
\end{tabular}

$r . h$. relative humidity

\section{Thermo-compression molding}

Thermo-compression molding of starch was conducted in a stainless steel mold designed with three $80 \times 10 \mathrm{~mm}^{2}$ rectangular cavities. As soon as the mold had reached the targeted processing temperature, the mold cavities were filled with $4.8 \mathrm{~g}$ of starch powder for each sample. Then powder was stacked by shaking the mold. Several processing temperatures $\left(80,90,100\right.$, and $\left.110{ }^{\circ} \mathrm{C}\right)$ were applied to the thermo-regulated plates of the molding press, while the pressure was kept constant at values that ranged from 25 to $100 \mathrm{MPa}$ during $60 \mathrm{~min}$. After molding, extracted samples were stored at least 1 week in a climate-controlled room at $23{ }^{\circ} \mathrm{C}$ and $50 \%$ r.h. prior to characterization tests.

\section{Characterization methods}

\section{Absolute density measurements}

A helium pycnometer (Accupyc 1330, Micromeritics Instrument Corporation, USA) was used to accurately measure the volume of starch granules. The volume determination is based on the reduction of gas capacity in a sample chamber caused by the presence of the starch powder. In practice, the device measures the pressure drop when the sample chamber is connected to an expansion chamber. Experiments were conducted in triplicate. Based on these measurements and the accurate determination of the powder mass, it was possible to calculate the absolute density of starch granules which was found to be $\rho_{\mathrm{abs}}=1.495 \pm 0.001 \mathrm{~g} \mathrm{~cm}^{-3}$.

\section{Bulk density measurements}

The mass of samples was determined with a Mettler Toledo ME204 balance. The thickness and width were measured with a Mitutoyo Digimatic 293-821 micrometer. Three measurements at different locations were used to define a mean value. The length was measured with a Mitutoyo Absolute Digimatic 500-181 caliper and the volume determined with the dimensional measurements based on a reasonable assumption of a plane-parallel geometry. Eventually, the sample bulk density $\rho_{\text {bulk }}$ was evaluated based on mass and volume values. The bulk porosity of samples was determined as follows:

$\Phi=1-\frac{\rho_{\text {bulk }}}{\rho_{\text {abs }}}$.

\section{Differential scanning calorimetry (DSC)}

Thermal analyses were performed under a nitrogen flow of $20 \mathrm{~mL} \mathrm{~min}^{-1}$. The Q100 equipment (TA Instruments, USA) was calibrated with zinc and indium standards. Samples $(8-12 \mathrm{mg}$ ) were put into aluminum pans and heated at a rate of $10{ }^{\circ} \mathrm{C} \mathrm{min}{ }^{-1}$. All experiments were conducted in triplicate.

\section{Thermogravimetric analysis (TGA)}

Thermogravimetric analysis (STA 6000, Perkin Elmer Instruments, USA) was performed to monitor the evaporation of water out of starch during heating under a nitrogen flow of $20 \mathrm{~mL} \mathrm{~min}{ }^{-1}$. Samples (8-12 mg) were placed in ceramic pans and heated at a rate of $10{ }^{\circ} \mathrm{C} \mathrm{min}{ }^{-1}$. All experiments were conducted in duplicate.

\section{Oedometer test}

The behavior of starch powder under confined compressive stress was assessed at room temperature using oedometer tests. Powder was placed in a cylindrical die of $12.5 \mathrm{~mm}$ in diameter and between two punches of the same diameter. The compression stress was applied by the upper punch which was displacement-controlled at a rate of $1 \mathrm{~mm} \mathrm{~min}^{-1}$. 
Three-point bending test

The mechanical behavior of samples was characterized by 3-point bending tests. An Instron 5965 testing machine was used with a $50 \mathrm{~N}$ force sensor. Considering the low stress levels, the deformation of the testing machine was neglected, and strain calculations were based on the crosshead displacement. Samples were stored and characterized in a climatecontrolled room at $23{ }^{\circ} \mathrm{C}$ and $50 \%$ r.h such that all samples had a similar water content before testing $(\approx 13 \mathrm{wt} \%)$. Experiments were conducted with a crosshead speed of $2 \mathrm{~mm} \mathrm{~min}^{-1}$ and in accordance with ISO178 standard.

\section{Scanning electron microscope (SEM)}

The morphology of samples was analyzed using a FEI $^{\mathrm{TM}}$ Quanta 200 scanning electron microscope. Images were recorded in secondary electron mode, after surface coating with an Emitech K550X goldpalladium coating device.

\section{$X$-ray diffraction $(X R D)$}

Native starch granules and compacted starch materials were ground to a fine powder and poured into glass capillaries of $1.5 \mathrm{~mm}$ outer diameter. The capillaries were flame-sealed and exposed to X-rays in a vacuum chamber using a Philips PW3830 generator operating at $30 \mathrm{kV}$ and $20 \mathrm{~mA}$ (Ni-filtered $\mathrm{CuK} \alpha$ radiation, $\lambda=0.1542 \mathrm{~nm}$ ). Two-dimensional diffraction patterns were recorded on Fujifilm imaging plates. The plates were read off-line using a Fujifilm BAS 1800-II bio-imaging analyzer. The resulting digitized ring patterns were radially averaged in order to obtain diffraction profiles.

\section{X-ray microtomography}

X-ray microtomography imaging experiments were performed at the European Synchrotron Radiation Facility (ESRF, ID19 beamline, Grenoble, France) to obtain 3D images of the microstructure of the center of samples (X-ray energy $=19 \mathrm{keV}, \mathrm{CCD}$ detector of $2048 \times 2048$ pixels, voxel size $0.324 \mu \mathrm{m} \times$ $0.324 \mu \mathrm{m} \times 0.324 \mu \mathrm{m}$, scanning time $<5 \mathrm{~min}$ ). The samples were placed vertically (length always orthogonal to the beamline during scanning). Reconstructed scans were treated using ImageJ software (U.S. National Institute of Health, Bethesda, USA) [10] in order to binarize the images (between starch and pores) and to filter noise. Typical resulting images before and after treatment are shown in Fig. 2. Porosity measurements within the sample core were made using volumes of $324 \mu \mathrm{m} \times 324 \mu \mathrm{m} \times$ $324 \mu \mathrm{m}$. The so-called core porosity was calculated, using the binarized 3D images, as the ratio between the sum of the black voxels, i.e., the volume occupied by the pores, and the sum of all voxels, i.e., the volume of the imaged specimen.

\section{Results}

\section{Preliminary experiments}

\section{Thermal behavior}

The thermal behavior of starch was investigated to estimate the optimal processing temperature range that allowed the native starch structure to be preserved. DSC and TGA analyses were performed on starch with different water contents (Fig. 3). The DSC device did not allow hermetic lids to be used, resulting in a decrease in water content during the experiments due to vapor leakage. However, these conditions were similar to those of thermo-compression molding.

TGA data showed a weight loss from 30 to $150{ }^{\circ} \mathrm{C}$ attributed to the vaporization of water as temperature increased, while calorimetric data showed that at least one endothermic phenomenon occurred from 30 to $200{ }^{\circ} \mathrm{C}$. Consequently, the heat flux variations above $150{ }^{\circ} \mathrm{C}$ were attributed to the melting of starch, whereas the variations below $150{ }^{\circ} \mathrm{C}$ implied that the melting of starch and the vaporization of water occurred simultaneously. From these data, it was not possible to determine the temperature at which melting started. Note also that samples mass and heating rate were slightly varied without significantly affecting the thermograms. However, as shown in Fig. 1, the peak temperature decreased with increasing water content. It indicated an approximate temperature range $\left(80-110^{\circ} \mathrm{C}\right)$ for which the melting of starch was expected to be limited.

\section{Compressibility}

To optimize the compressive stress during thermocompression molding, several oedometer tests were 
Figure 2 Cross-sections of X-ray microtomography images before (a) and after (b) binarization (pictures represent a square of $324 \mu \mathrm{m}$ side length) - location of the cross-section in the $3 \mathrm{D}$ volume (c).

(a)
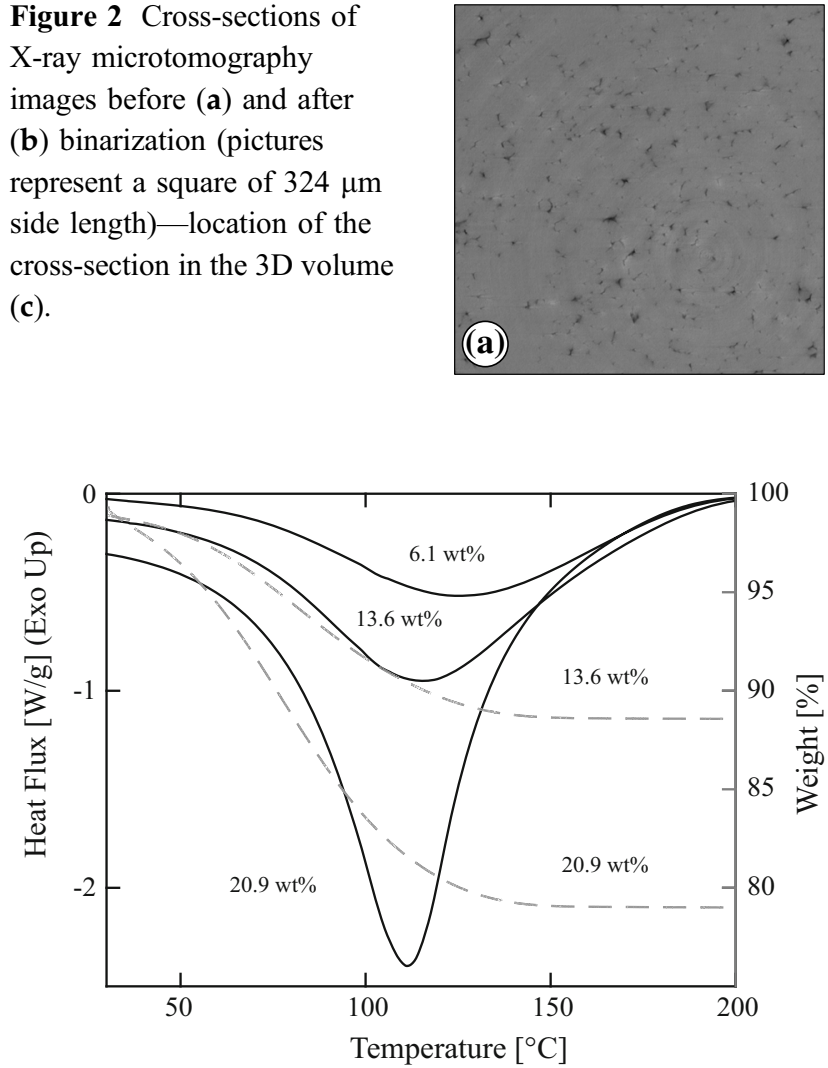

Figure 3 DSC and TGA (dotted line) thermograms during heating of starch at $10{ }^{\circ} \mathrm{C} \mathrm{min}^{-1}$.

conducted at room temperature on starch powder with different water contents. Figure 4 presents the evolution of the compressive stress as a function of bulk density during loading. For a given compressive stress, the bulk density increased with increasing water content. For high water contents, the stressstrain curves exhibited a kink that appeared because the bulk density of samples approached the absolute density of starch particles, i.e., $1.495 \mathrm{~g} \mathrm{~cm}^{-3}$. This sudden change in slope was emphasized by the low compressibility of water trapped in the pores of the compacted pellets. From these results, an approximate range for compressive stress (25-100 MPa) and water content (10-20 wt\%) was evaluated, so as to reach a maximal density at room temperature.

\section{Thermo-compression molding}

\section{Visual aspect}

Based on the evolution of starch behavior as a function of water content, samples with different water
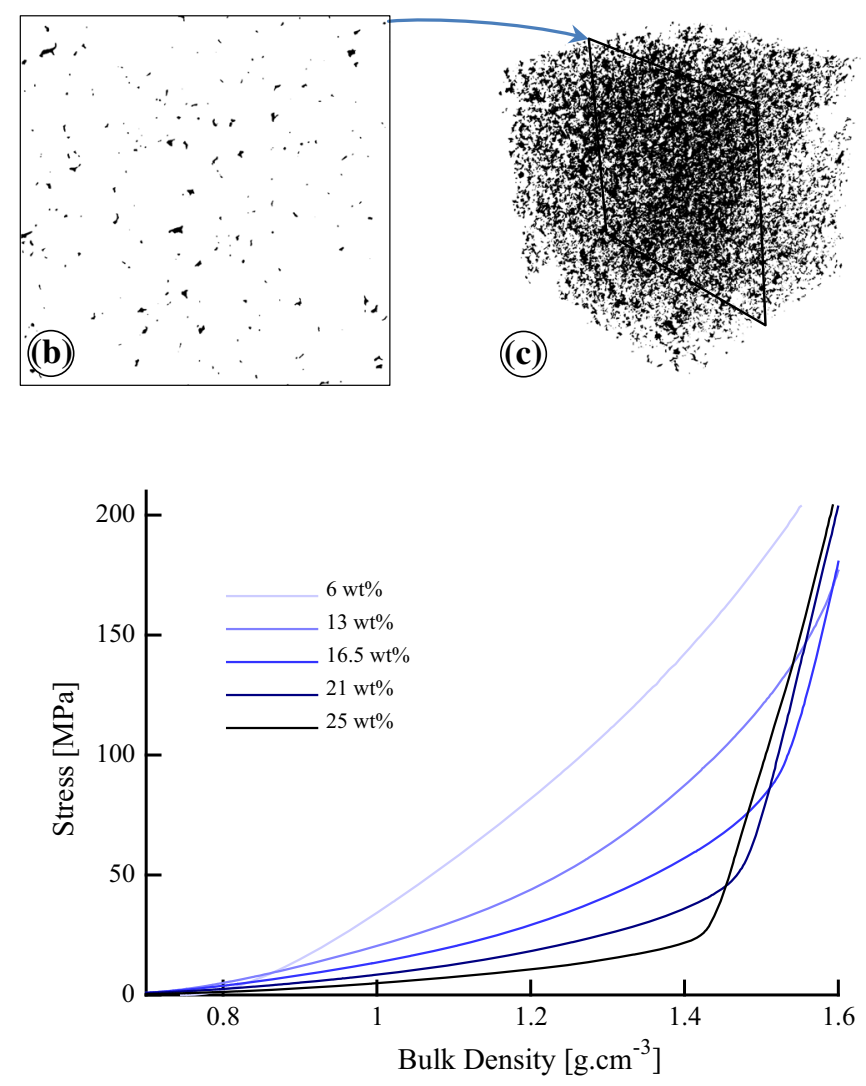

Figure 4 Compressive stress as a function of bulk density during loading of oedometer tests of starch to $200 \mathrm{MPa}$ at room temperature and for different water contents.

contents were processed by thermo-compression molding to evaluate the best processing conditions. The processing conditions tested, depending on water content, are summarized in Table 2. Prior to any characterization, the appearance of processed samples was evaluated (Fig. 5).

- All samples prepared from the as-received starch (13 wt\% water content) were visually uniform and cohesive. They all showed a similar yellowish color and their surface was smooth, although samples processed at $80^{\circ} \mathrm{C}$ and 25 or $50 \mathrm{MPa}$ were whiter and their surface was mat.

- Thermo-compression molding was also conducted on hydrated starch (19 wt\% water content). For several conditions $\left(80{ }^{\circ} \mathrm{C}-100 \mathrm{MPa}\right.$, $\left.90{ }^{\circ} \mathrm{C}-50 \mathrm{MPa}\right)$, hydrated starch turned into a gel flowing out of the mold. Consequently, the processing temperature and compressive stress had to be lowered to avoid starch gelatinization and thus leakage from the mold. At $25 \mathrm{MPa}$ and below $80{ }^{\circ} \mathrm{C}$, the samples were heterogeneous and 
Table 2 Processing parameters used for thermo-compression molding depending on starch water content

\begin{tabular}{llll}
\hline Water content $(\mathrm{wt} \%)$ & 6 & 13 & 19 \\
Temperature $\left({ }^{\circ} \mathrm{C}\right)$ & $90-150$ & $80-110$ & $70-90$ \\
Compressive stress $(\mathrm{MPa})$ & 100 & $25-100$ & $25-100$ \\
\hline
\end{tabular}

presented an unusual skin/core structure (Fig. 5c). While the core appeared to be dense and stiff, the surface of the samples was cracked and crumbly. Decreasing temperature below $70{ }^{\circ} \mathrm{C}$ would necessitate increasing water content and compressive stress in order to achieve sintering, thus increasing the risk of leakage of the starch-water mixture from the mold.

- Samples were also processed with dried starch (6 wt\% water content). Due to the low compressibility of dried starch (cf. Compressibility), the samples were only processed at a compressive stress of $100 \mathrm{MPa}$. The samples prepared at a processing temperature ranging from 90 to $150{ }^{\circ} \mathrm{C}$ looked similar and were visually satisfactory after ejection. However, cracks appeared after a few minutes, and samples started crumbling and breaking as they were cooling down. These results revealed a weak cohesion between starch granules. It is worth noting that a higher processing temperature resulted in less cracks. This suggests that the processing temperature and compressive stress should be much higher than those used in this study. However, this would imply a significant increase in the energy required for the forming process.

Therefore, the plasticizing effect of water increasing the macromolecular mobility proved to be essential in the mechanisms of granule welding. For hydrated starch, in agreement with previous observations (cf. Thermal behavior and Compressibility), the processing temperature and compressive stress
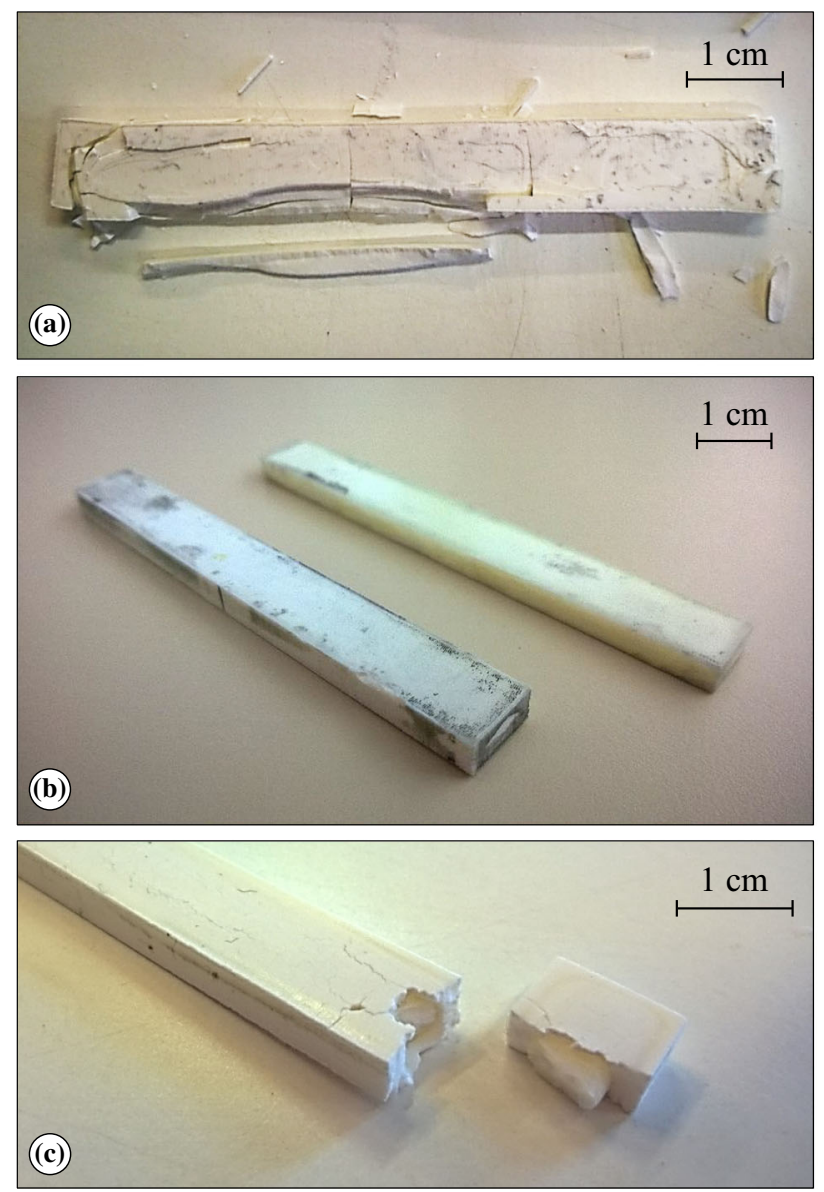

Water content: $\mathbf{6} \mathbf{w t} \%$

$150^{\circ} \mathrm{C}$ and $100 \mathrm{MPa}$

Water content: $13 \mathbf{~ w t} \%$

$80^{\circ} \mathrm{C}$ and $25 \mathrm{MPa}$

(foreground)

$80^{\circ} \mathrm{C}$ and $100 \mathrm{MPa}$

(background)

Water content: 19 wt $\%$

$70^{\circ} \mathrm{C}$ and $25 \mathrm{MPa}$

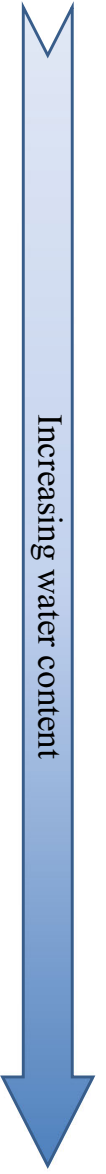

Figure 5 Photographs of samples obtained by thermo-compression molding with different initial water contents of starch: a 6 wt $\%$, b $13 \mathrm{wt} \%$, c $19 \mathrm{wt} \%$. 

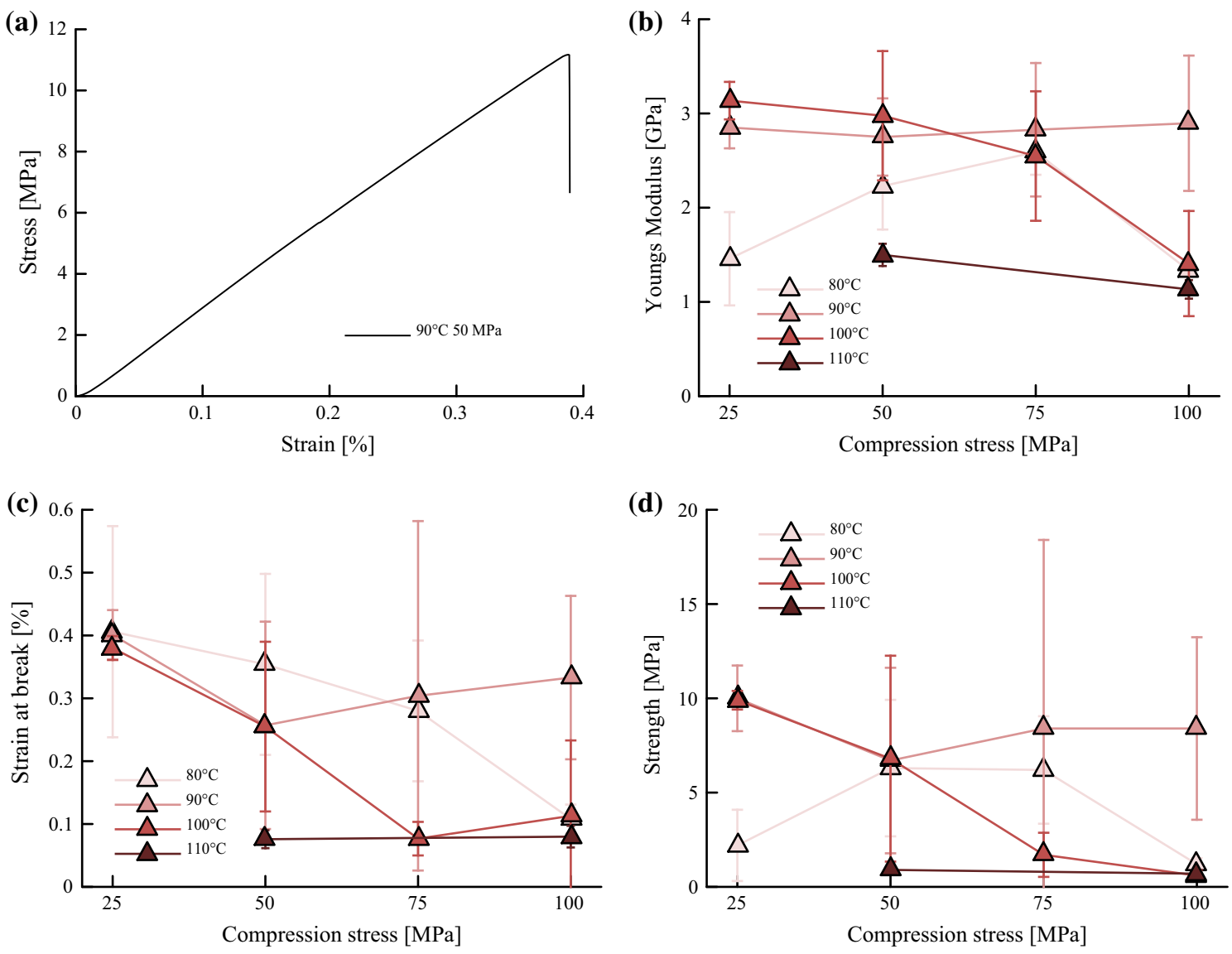

Figure 6 Stress-strain curve (a), Young's modulus (b), strain at break (c), and strength (d) of starch samples as a function of processing temperature and compressive stress (initial water content of starch of $13 \mathrm{wt} \%$ ).

were suitably selected. However, the skin-core structure of these samples remained a major problem. As a result, visual inspections allowed concluding that among all tested samples, the optimal water content was that of the as-received starch.

\section{Mechanical properties}

The sample appearance was not the only factor to take into consideration to evaluate the optimal processing conditions. The mechanical properties were also assessed by three-point bending tests.

Figure 6a shows that the mechanical behavior of starch samples was almost linear and fragile. Despite an important dispersion in the results, samples exhibited Young's moduli of approximately $3 \mathrm{GPa}$ (Fig. 6b). The flexural strength varied between 1 and $10 \mathrm{MPa}$ (Fig. 6c). The ductility was poor and strain at break rarely exceeded $0.4 \%$ (Fig. $6 \mathrm{~d}$ ).
Several remarks can also be drawn from Fig. 6. First, increasing the compressive stress during thermo-compression molding did not induce any increase in the mechanical properties, except for samples processed at $80^{\circ} \mathrm{C}, 25 \mathrm{MPa}$, and $50 \mathrm{MPa}$. In addition, above $100{ }^{\circ} \mathrm{C}$, the processing temperature had a negative influence on the mechanical properties. Finally, optimal processing conditions were obtained for temperatures between 90 and $100{ }^{\circ} \mathrm{C}$ and at $25 \mathrm{MPa}$.

\section{Crystallinity}

The crystal structure of samples was characterized using XRD and compared to that of native starch. In agreement with the literature data, the XRD profile of native starch shown in Fig. 7 corresponds to allomorph A, with the main peaks located at about $15^{\circ}$, $17^{\circ}, 18^{\circ}$, and $23.3^{\circ}$ diffraction angles. In addition, the 


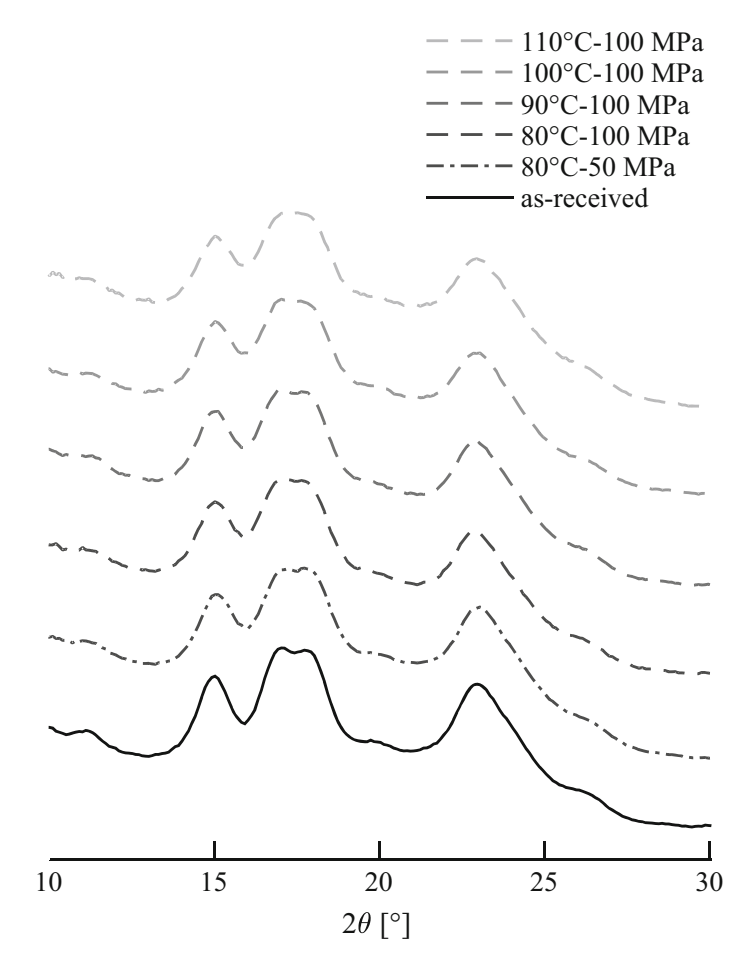

Figure 7 XRD profiles of starch after thermo-compression molding according to different processing conditions (initial water content of starch of $13 \mathrm{wt} \%$ ).

loss of crystallinity induced by thermo-compression molding was limited and depended neither on the processing temperature nor on the compressive stress. This result shows that thermo-compression molding was effective for preserving the crystalline structure of starch.

\section{Microstructure}

The previous results show that the conditions resulting in the best mechanical properties are also those leading to the lower dispersions in repeatability. This observation suggests that the dispersion of properties for samples obtained using the same process parameters was induced by the presence of defects. Therefore, in the following sections, these defects were analyzed by observing the microstructure of molded starch samples.

\section{Morphology of fracture surfaces}

The morphology of the fracture surface of samples resulting from three-point bending tests was observed by optical and scanning electron microscopy. Apart from samples processed at $80^{\circ} \mathrm{C}$,
$25 \mathrm{MPa}$ and $50 \mathrm{MPa}$, which exhibited a higher porosity (cf. Porosity), the fracture surfaces were similar for all other samples (Fig. 8).

Fracture surfaces were highly heterogeneous, with a large part of the region located in the center (region I) that exhibited a smooth surface, despite some micro-cracks (Fig. 8a). This smoothness reveals that, when the samples were broken, the fracture propagated through starch granules, indicating an excellent cohesion between them. Around this region and up to the outer surface of samples (region II), the quality of compaction and welding varied. Most of in-plane cracks had propagated through granules, whereas several out-of-plane cracks of all sizes which had propagated between granules were visible (Fig. 8d), indicating poor cohesion between granules at the time the crack appeared.

Beside these wide regions, the corners of the crosssections presented two different morphologies depending on their location. Corners which were in contact with the bottom of the mold (region III) showed a poor compaction and a poor cohesion between granules (Fig. 8e) attributed to the lower compression stress in this area because of starch/mold friction. Corners which were in contact with the die (regions IV) showed particularly distorted granules (Fig. 8c) under the high shear stress in these regions.

A different region could sometimes be identified within the cross-section (region V). Although its location varied from one sample to another, it was generally found near the rim of the cross-section. Despite the presence of micro-cracks, the compaction was very good in this region, but the surface was particularly uneven and starch granules could be easily identified (Fig. 8b), suggesting a crack that propagated between granules. Based on the hypothesis that the fracture of the samples grew from a defect inside the material, this observation suggests that this region was the remainder of a pre-existing crack oriented in the cross-section plane and resulting from processing. The crack might have propagated to the rest of the cross-section during the bending test. This assumption, if true, implies that the intergranular cracks observed in region II occurred during the forming process before full cohesion between granules was achieved.

Yet this typical morphology slightly varied depending on the processing conditions. In particular, region I became visually darker with increasing 


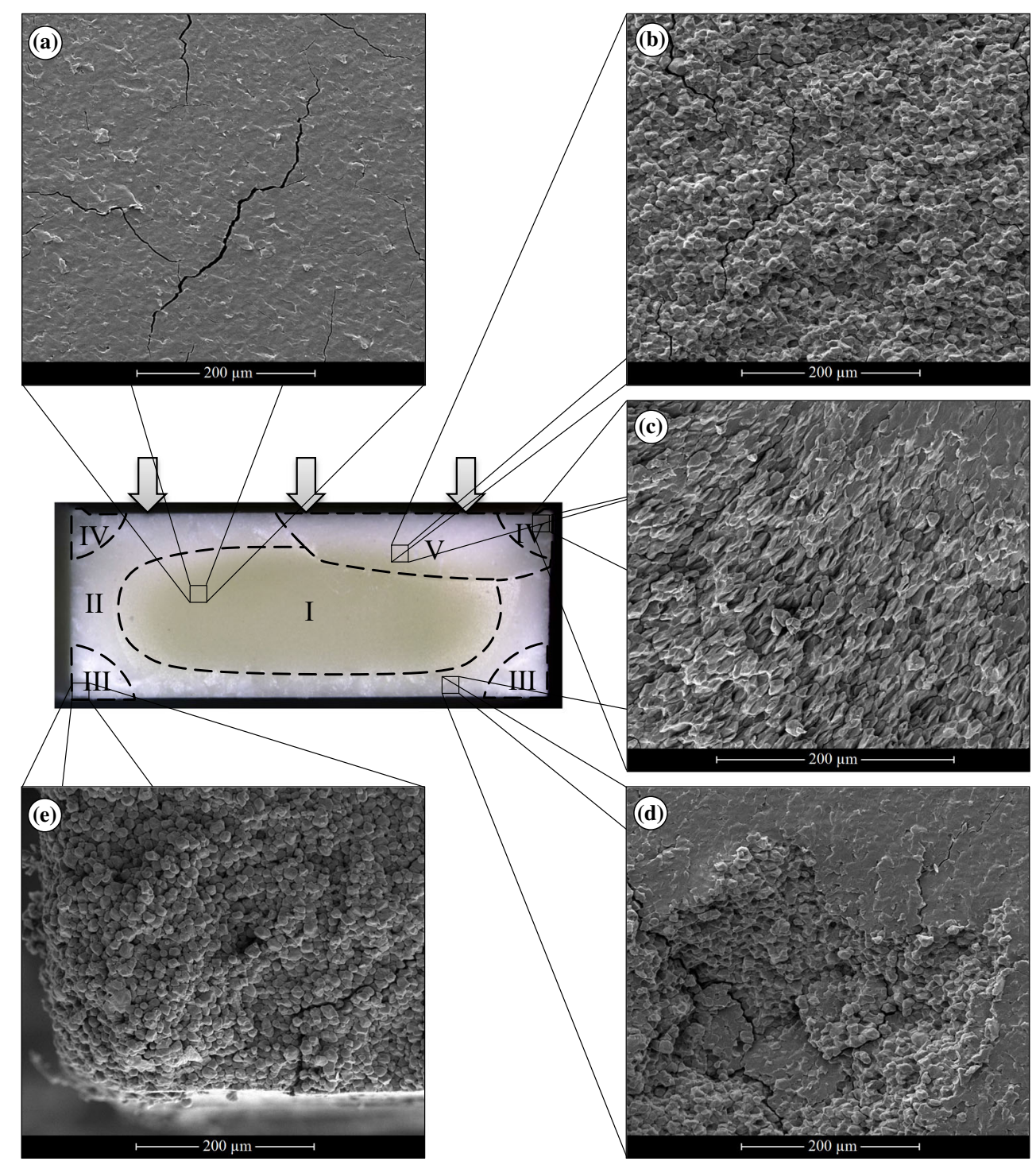

Figure 8 Fracture surface of starch compacted by thermo-compression molding at $100{ }^{\circ} \mathrm{C}$ and $100 \mathrm{MPa}$ during $1 \mathrm{~h}$ (initial water content of starch of $13 \mathrm{wt} \%)$.

temperature. For the highest processing temperatures $\left(100\right.$ and $\left.110{ }^{\circ} \mathrm{C}\right)$ and $100 \mathrm{MPa}$, the fracture surfaces often exhibited relatively large out-of-plane cracks that could be at the origin of the poor mechanical properties of these samples.

\section{Porosity}

The bulk porosity of samples was plotted as a function of processing temperature and compressive stress (Fig. 9a). Values were very similar and ranged from 3 to $4 \%$, except for samples processed at $80^{\circ} \mathrm{C}$ and 25 or $50 \mathrm{MPa}$, which reached 8 and $5 \%$, respectively. This result is consistent with microscopic observations (cf. Morphology of fracture surfaces) and with the whiter aspect of these samples (cf. Visual aspect). The porosity of the other samples could not be decreased below $3 \%$, despite the increase of both temperature and compressive stress.

The core porosity of the samples is shown in Fig. $9 \mathrm{~b}$. The results confirm that the core porosity was substantially affected by the processing temperature at $25 \mathrm{MPa}$. Globally, core porosity values were slightly lower than bulk porosity values. The difference increased and reached a maximum of $3 \%$ as the porosity decreased. The differences between bulk and core porosities were attributed to the appearance of numerous cracks close to the surface of the 

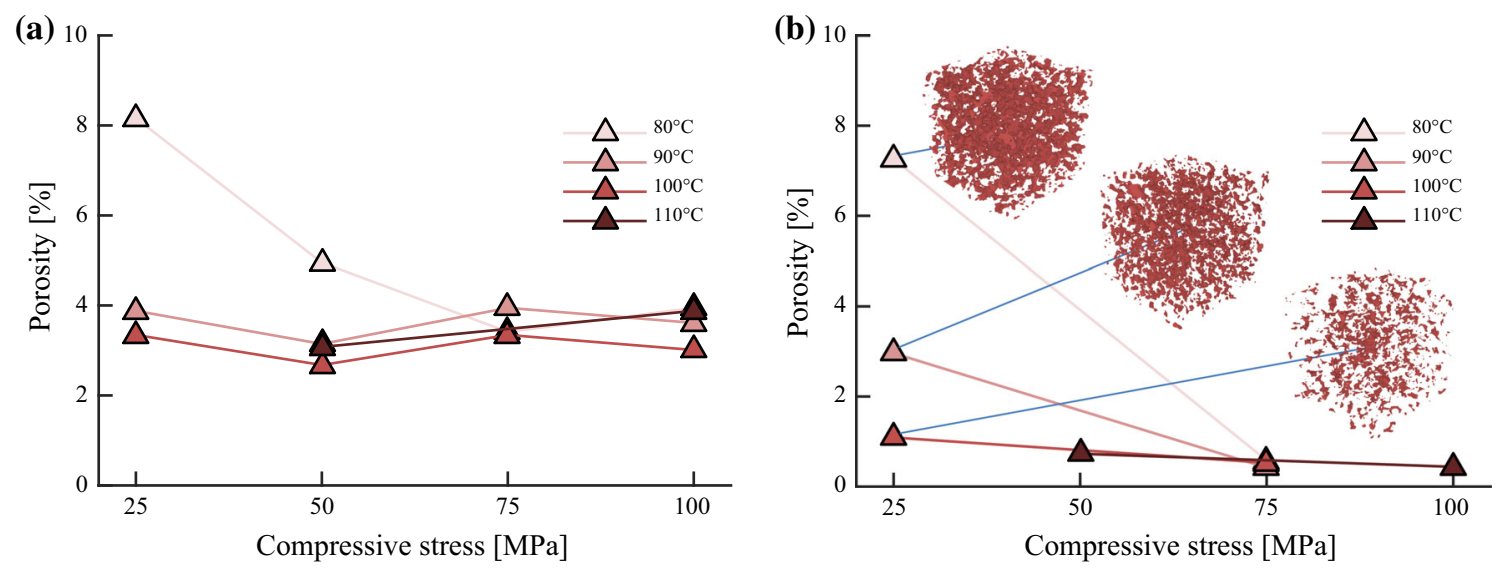

Figure 9 Bulk (a) and core (b) porosities of starch samples as a function of processing temperature and compressive stress (initial water content of starch of $13 \mathrm{wt} \%)$.

samples (regions II, III, and IV in Fig. 8), while the central part (within which the microtomography scans were performed) was less affected. These results suggest that the surrounding areas of the samples were more prone to cracking for higher temperatures and compressive stresses. These cracks are supposed to be very different from pores which resulted from the remainder of intergranular voids after compaction.

The results also revealed the links between the porosity and the mechanical properties of samples. For instance, increasing temperature and compressive stress up to $80^{\circ} \mathrm{C}$ and $75 \mathrm{MPa}$ or $90{ }^{\circ} \mathrm{C}$ and $50 \mathrm{MPa}$ resulted in a lower porosity and higher modulus and flexural strength of the samples (Fig. 6). In this case, both bulk and core porosities were affected. Above these values, increasing temperature or compression stress did not improve compaction anymore but increased skin crack density resulting in an overall decrease of mechanical properties (Fig. 6) and a slight increase in bulk porosity (Fig. 9). In this case, the core porosity was not affected, since no cracks were detected in the microtomography scans.

\section{Discussion}

The results showed that the mechanical performance of compacted starch samples depended on an appropriate choice of temperature, moisture content, and compressive stress. All these factors affected the quality of compaction and welding of starch granules. In specific conditions, the resulting samples exhibited regions where compaction and welding were very good. However, the samples were always heterogeneous because of defects such as localized cracks and poorly compacted areas. In the following sections, the conditions for good compaction and welding of starch granules, as well as the potential causes for these defects are discussed.

\section{Mechanisms of compaction and welding}

While increasing the water content, temperature, and compressive stress together, the samples evolved by going through the four following states (by order of appearance):

A. Low compaction (high porosity), no cohesion (gaps between granules) (Fig. 10a),

B. Good compaction, low cohesion (still possible to distinguish granules) (Fig. 10b),

C. Good compaction, good cohesion (almost homogenous phase) (Fig. 10c), and

D. Gelatinization (leakage from the mold) (not shown in Fig. 10).

As a result, thermo-compression of starch induced three possible mechanisms: compaction (deformation of granules, reduction of intergranular voids), welding (mechanical adhesion at the interface between granules), and gelatinization (loss of the semicrystalline structure of granules).

The starch water content was the most sensitive parameter to control these mechanisms, as shown in Fig. 5. Water acts as a plasticizer of polymers [11] and increases macromolecular chain mobility. Thus, the 

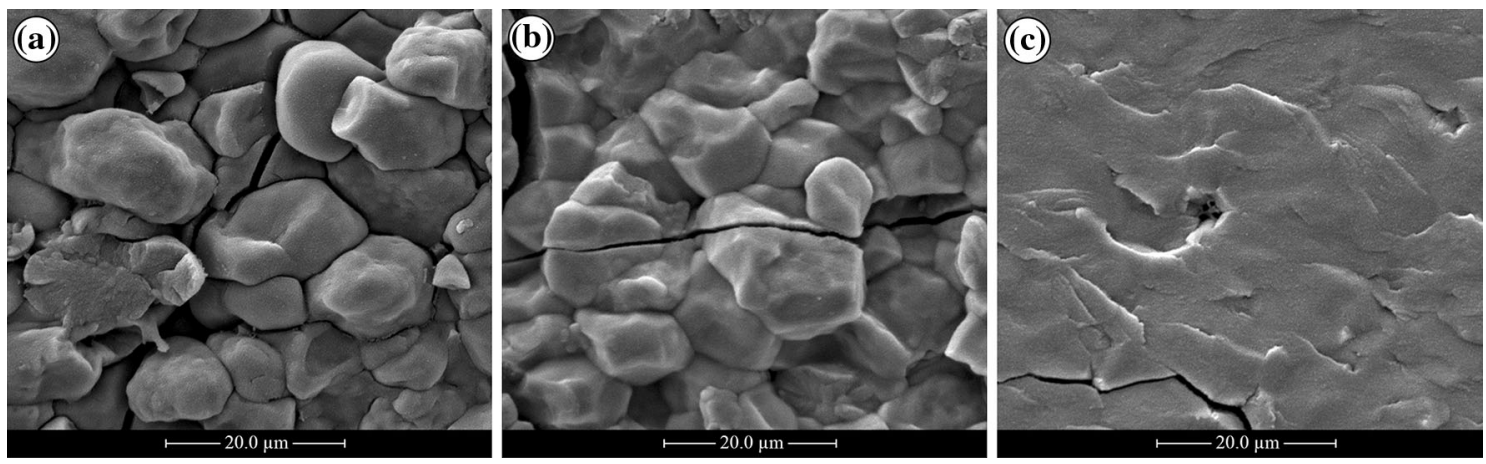

Figure 10 SEM images of failure patterns in regions III (a), V (b), and I (c) of thermo-compression molded starch samples.

increase in water content potentially improves compaction by lowering phase transition temperatures (Fig. 3) and increasing deformability (Fig. 4). When changing starch water content, the temperature and compaction stress needed to be adjusted accordingly to achieve satisfactory compaction and welding.

As water content was increased, both temperature and compressive stress were lowered to avoid gelatinization and leakage from the mold. Indeed, while it was shown [6] that starch gelatinization does not occur at atmospheric pressure with a water content below $30 \mathrm{wt} \%$ (Fig. 1), it was also demonstrated [12] that native starch could be gelatinized at room temperature above $500 \mathrm{MPa}$. In the present study, gelatinization of starch granules was observed at $19 \mathrm{wt} \%$ water content when starch was subjected to a compressive stress, confirming the dependence of gelatinization to pressure.

On the contrary, for dry starch, the processing temperature and compaction stress needed to be increased in order to obtain a cohesive material. However, despite a considerable increase in both temperature and compressive stress, we were unable to achieve the aforementioned state $\mathrm{C}$ using dry starch.

\section{Potential origins of defects and heterogeneities}

The presence of defects within the samples resulted from process-induced defects such as remaining pores or insufficiently cohesive contacts between granules coupled with residual stresses causing crack propagation. It was shown that the distribution of the defects in the samples was particularly heterogeneous (cf. Microstructure). The reason of this heterogeneity and the clues it gives about the origin of the defects were investigated in this section.

\section{During thermo-compression molding}

During processing, heating induced the drying of starch due to vapor expelling from the non-hermetic mold. Immediately after ejection of the mold of asreceived starch processed at $80{ }^{\circ} \mathrm{C}$ and $100 \mathrm{MPa}$, the overall water content was measured to be $6 \mathrm{wt} \%$ (vs. $13 \mathrm{wt} \%$ before processing).

The drying of starch resulted in a poor cohesion between granules as shown in Fig. $5 \mathrm{a}$ for the samples with an initial water content of $6 \mathrm{wt} \%$. This observation was related to lower molecular mobility of starch macromolecular chains and to drying-induced granules shrinkage [13]. To illustrate this phenomenon, Fig. 11a shows the macroscopic strain resulting from the drying of compacted as-received starch powder when exposed to a dry atmosphere $\left(23{ }^{\circ} \mathrm{C}\right.$ and $10 \%$ r.h.). Both phenomena induced a poorer compaction due to the increase in granule stiffness, and thus reduced contact surfaces and larger porosities. During thermo-compression molding, drying probably occurred close to the surface (region II) before cohesion was complete, whereas within the core (region I), diffusion toward region II was slow enough for cohesion/welding to be complete. Such mechanisms explain the difference between regions I and II in Fig. 8. This difference is even more striking in the core-skin structure of hydrated samples (Fig. 5c). In this case, cracks on the surface of samples were so wide that they could be observed with the naked eye.

\section{After ejection}

Thermal shrinkage vs. hygroscopic swelling Figure 11 shows that drying and hydration of starch induce hygroscopic shrinkage and swelling strains within 


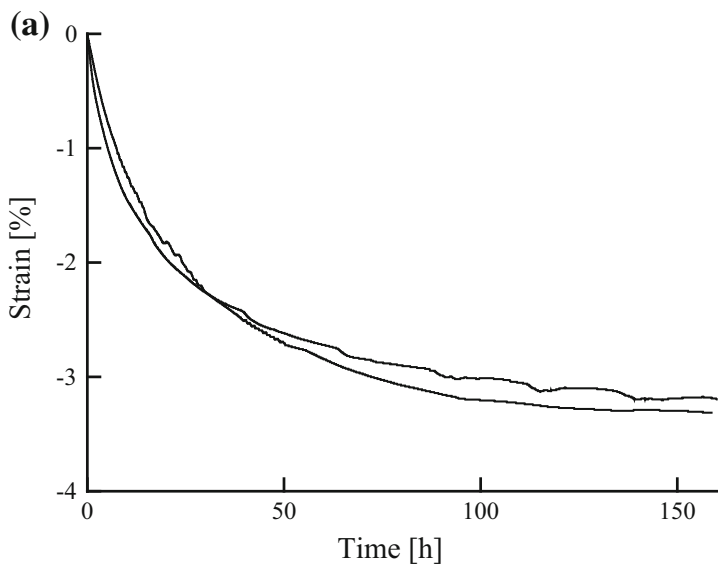

Figure 11 Hygroscopic strain of compacted starch by oedometer test (200 MPa) a as-received starch (initial water content of starch of $13 \mathrm{wt} \%$ ) during exposition to a dry atmosphere (10\% r.h.),

stress-free samples, respectively. Therefore, it is expected that such dimensional variations occur after ejection of samples, possibly resulting in the propagation of cracks, starting from remaining porosities or low-cohesion bonds between granules. Additional shrinkage is also expected due to the cooling of samples. For this reason, the evolution of the sample thickness was measured with a digital indicator as a function of time, immediately after their ejection from the mold (Fig. 12).

The inset in Fig. 12 shows that shrinkage prevailed in the first hour after the ejection of the samples, followed by swelling. The shrinkage was attributed to the effect of both drying and cooling. Figure 13 shows the weight change right after ejection from the mold. The record of the weight change brings evidence that during the first minutes after the beginning of the test, water was still vaporizing before starch had cooled down. However, after approximately $3 \mathrm{~min}$, the weight change became positive, indicating starch water absorption from ambient atmosphere. Yet the samples still underwent shrinkage until $1 \mathrm{~h}$ after ejection, indicating that thermal shrinkage prevailed over hygroscopic swelling in this period.

After $1 \mathrm{~h}$, swelling was very slow (equilibrium not reached after $24 \mathrm{~h}$ ) and rather limited compared to the initial shrinkage (Fig. 12). The differences observed in terms of magnitude between the total shrinkage (thermal and hygroscopic) and swelling strain suggest that most of the observed shrinkage was due to cooling. Neglecting other causes than

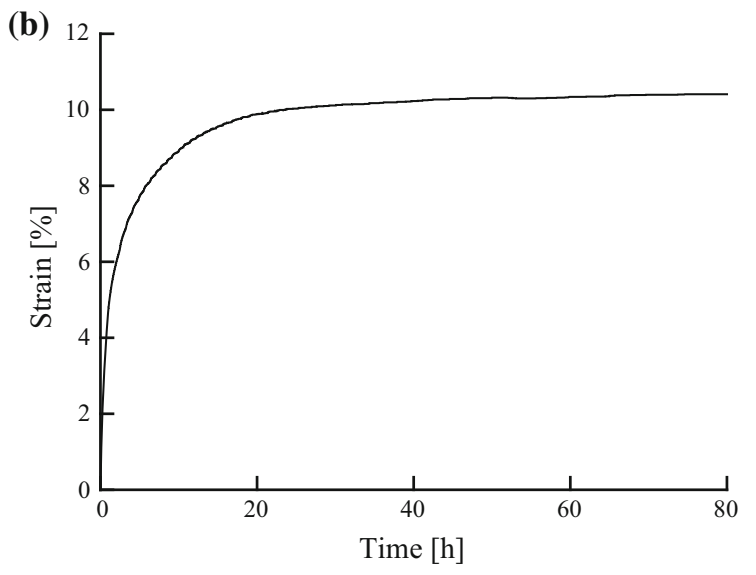

b dried starch (initial water content of starch of $6 \mathrm{wt} \%$ ) during exposition to standard conditions (50\% r.h.).

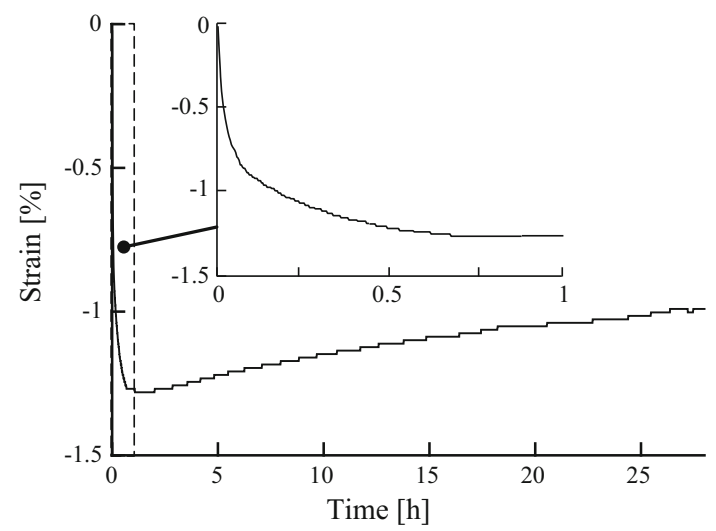

Figure 12 Strain after ejection of compacted starch by thermocompression molding at $100{ }^{\circ} \mathrm{C}$ and $100 \mathrm{MPa}$ during $1 \mathrm{~h}$ (initial water content of starch of $13 \mathrm{wt} \%$ ).

thermal shrinkage within this time period, it is possible to evaluate an upper bound for the coefficient of thermal expansion, which was found to be $180 \times 10^{-6} \mathrm{~K}^{-1}$. This value is close to the largest values found in the literature [14, 15]. The corresponding shrinkage strain $(\approx-1.3 \%)$ was significant, especially for such a fragile material (flexural strain at break $\leq 0.4 \%$ in Fig. $6 \mathrm{c}$ ). It is then reasonable to think that the degradation of mechanical properties for processing temperatures higher than $90{ }^{\circ} \mathrm{C}$ (Fig. 6) was caused by larger thermal stress gradients inducing more significant cracks. Such a mechanism is consistent with the observation that samples processed with initially dried starch crumbled after a few minutes while cooling down (Fig. 5). The significant 


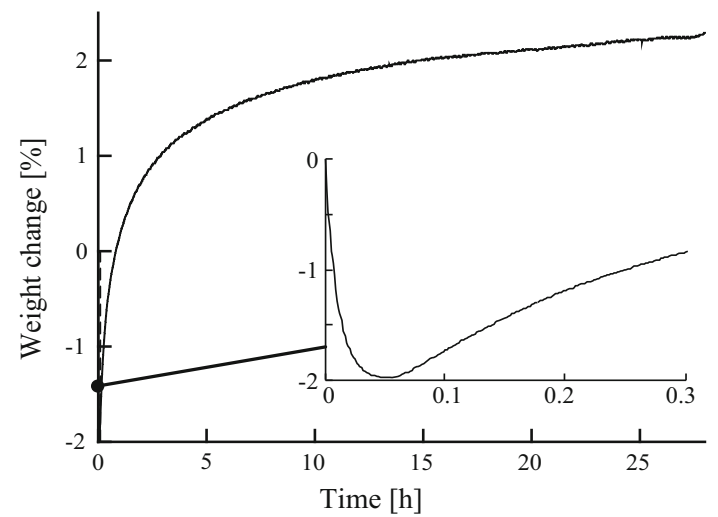

Figure 13 Weight change after ejection of compacted starch by thermo-compression molding at $100{ }^{\circ} \mathrm{C}$ and $100 \mathrm{MPa}$ during $1 \mathrm{~h}$ (initial water content of starch of $13 \mathrm{wt} \%$ ).

strain induced by thermal shrinkage overcame the low strain at break resulting from the poor cohesion.

Effect of viscoelastic recovery Another phenomenon to be taken into account was the viscoelastic recovery after the removal of the compressive stress. As usual for polymers, the resulting strain is the combination of an instantaneous (purely elastic) part and a time-dependent (viscoelastic) part. While instantaneous elastic springback certainly was a cause for cracking, the order of magnitude of the time-dependent recovery strain was qualitatively estimated to assess its potential effect on delayed cracking. To isolate the time-dependent viscoelastic strain from the hygroscopic swelling occurring during thermo-compression molding, starch compression tests were conducted at room temperature. Oedometer tests at $200 \mathrm{MPa}$ were carried out for the as-received starch (13 wt $\%$ water content) and dried starch ( $6 \mathrm{wt} \%$ water content). After ejection, the evolution of the height of samples was measured as a function of time in a controlled environment so as not to vary the initial starch water content (Fig. 14).

The results showed that the samples prepared from dried starch exhibited a more significant viscoelastic recovery and the transient regime was shorter. The previous results (cf. Mechanisms of compaction and welding) demonstrated that dried granules were less prone to compaction and exhibited less cohesion than as-received granules. These results suggest that the better the compaction and cohesion, the more limited the recovery and the longer the transient regime. In the case of thermo-compression molding, the effect of temperature is expected to enhance compaction and

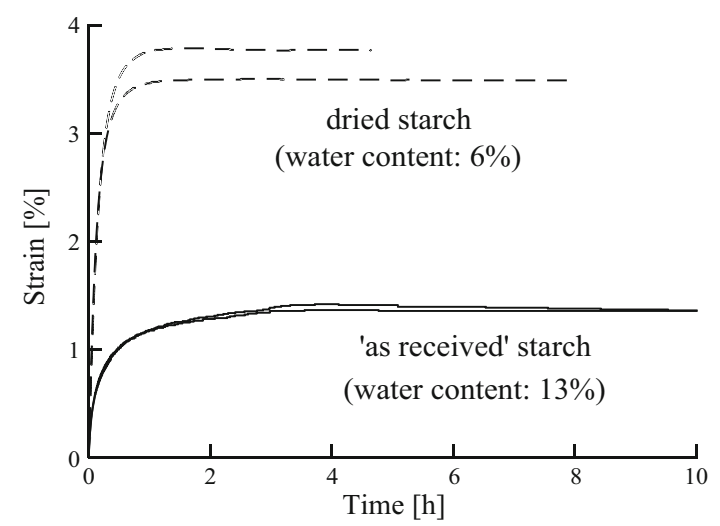

Figure 14 Viscoelastic strain of compacted the as-received and dried starch after oedometer test $(200 \mathrm{MPa})$ in a controlled atmosphere (initial water content of starch of $13 \mathrm{wt} \%$ ).

cohesion, inducing a longer transient regime. In such a scenario, recovery and swelling occur simultaneously, resulting in the amplitude of viscoelastic recovery being limited because (i) as it was already established, swelling is small compared to thermal shrinkage, (ii) compaction and cohesion were significantly improved by heating, and (iii) compressive stresses reached in thermo-compression molding were significantly smaller than in oedometer tests, as shown in Fig. 14.

\section{Conclusions}

This study investigated the possibility of manufacturing bulk materials from native starch powder, while preserving their native semicrystalline structure. This objective was successfully achieved using thermo-compression molding and a suitable combination of processing parameters such as temperature, compressive stress, and starch water content (i.e., $90{ }^{\circ} \mathrm{C}, 25 \mathrm{MPa}$, and $13 \mathrm{wt} \%$, respectively). It was shown that compaction and welding of starch granules could be obtained without affecting their semicrystalline structure. The essential role of water content was identified. An increase in water content potentially improves compaction and welding by lowering phase transition temperatures and increasing deformability of starch granules. When changing starch water content, temperature and compaction stress need to be adjusted. For instance, when water content increases, both temperature and compressive stress need to be lowered to avoid gelatinization. 
The resulting samples exhibited a Young's modulus comparable to those of usual thermoplastic matrices, despite the presence of defects such as porosity or cracks, negatively affecting strength properties. Potential causes for such defects occurring both during and after processing were discussed. During processing, porosity was induced by poor compaction, whereas cracks were caused by thermal and moisture gradients leading to shrinkage and hardening of starch granules preventing their coalescence. After ejection, cracks were induced by heterogeneous cooling of samples which resulted in stress induced by thermal gradients. On the contrary, the effect of time-dependent viscoelastic strain recovery was estimated to be rather limited. However, the effect of elastic springback after ejection should be carefully investigated.

Finally, the apparition of defects could be minimized by a less sudden change of temperature, water content, and compressive stress immediately after processing which could be achieved by a better control of processing parameters during this period.

\section{Acknowledgements}

The authors gratefully acknowledge Institut Carnot PolyNat for funding this study. Besides, they would like to thank S. Rolland du Roscoat, P. Charrier, B. Khelifi, D. Curtil, R. Passas, C. Sillard, and S. Dufreney for their technical support, as well as R. Léger from Centre des Matériaux des Mines d'Alès (C2MA) at École des mines d'Alès for assistance with pycnometer experiments. The LGP2 and 3SR laboratories are part of LabEx Tec 21 (Investissements d'AvenirGrant Agreement No. ANR-11-LABX-0030).

\section{References}

[1] Schroeter J, Hobelsberger M (1992) On the mechanical properties of native starch granules. Starch 44:247-252

[2] Buléon A, Potocki-Véronèse G, Putaux J-L (2007) Self-association and crystallization of amylose. Aust $\mathrm{J}$ Chem 60:706-718

[3] Salerno M, Żukowska A, Thorat S, Ruffilli R, Stasiak M, Molenda M (2014) High resolution imaging of native wheat and potato starch granules based on local mechanical contrast. J Food Eng 128:96-102

[4] Ceseracciu L, Heredia-Guerrero JA, Dante S, Athanassiou A, Bayer IS (2015) Robust and biodegradable elastomers based on corn starch and polydimethylsiloxane (PDMS). ACS Appl Mater Interfaces 7:3742-3753

[5] Yu L, Christie G (2000) Measurement of starch thermal transitions using differential scanning calorimetry. Carbohydr Polym 46:179-184

[6] Donovan JW (1979) Phase transitions of the starch-water system. Biopolymers 18:263-275

[7] Biliaderis CG, Page CM, Maurice TJ, Juliano BO (1986) Thermal characterization of rice starches: a polymeric approach to phase transitions of granular starch. J Agric Food Chem 34:6-14

[8] Day L, Fayet C, Homer S (2013) Effect of $\mathrm{NaCl}$ on the thermal behaviour of wheat starch in excess and limited water. Carbohydr Polym 94:31-37

[9] Biliaderis CG (2009) Structural transitions and related physical properties of starch. In: BeMiller J, Whistler R (eds) Starch-chemistry and technology. Academic Press, Thessaloniki, pp 293-372

[10] Dello SAWG, van Dam RM, Slangen JJG, van de Poll MCG, Bemelmans MHA, Greve JWWM, Beets-Tan RGH, Wigmore SJ, Dejong CHC (2007) Liver volumetry plug and play: do it yourself with ImageJ. World J Surg 31:2215-2221

[11] Fayolle B, Verdu J (2005) Vieillissement Physique des Matériaux Polymères, Techniques de l'Ingénieur Propriétés Générales des Plastiques AM3150:1-19

[12] Gebhardt R, Hanfland M, Mezouar M, Riekel C (2007) High-pressure potato starch granule gelatinization: synchrotron radiation Micro-SAXS/WAXS using a diamond anvil cell. Biomacromolecules 8:2092-2097

[13] Lozano JE, Rotstein E, Urbicain MJ (1983) Shrinkage, porosity and bulk density of foodstuffs at changing moisture contents. J Food Sci 48:1497-1502

[14] Millauer C, Rosa G, Schär R (1987) Determination of the density of starches and cereal products as a function of temperature and pressure. In: Meuser F, Manners DJ, Seibel W (eds) Plant polymeric carbohydrates. Woodhead Publishing, Cambridge, pp 86-103

[15] Nishiyama Y, Putaux J-L, Montesanti N, Hazemann J-L, Rochas C (2010) B $\rightarrow$ A allomorphic transition in native starch and amylose spherocrystals monitored by in situ synchrotron X-ray diffraction. Biomacromolecules 11:76-87 